\title{
Cyclosporin A Enhances Callus Formation in Rabbit Tibia Fractures*
}

\author{
Anders L. Ekelund ${ }^{1 \#}$, Olle Nilsson ${ }^{2 \#+}$ \\ ${ }^{1}$ Department of Orthopedic Surgery, St. Göran's Hospital, Stockholm, Sweden; ${ }^{2}$ Department of Orthopedic Surgery, Uppsala Uni- \\ versity Hospital, Uppsala University, Uppsala, Sweden. \\ Email: ${ }^{\dagger}$ Olof.Nilsson@akademiska.se
}

Received April $8^{\text {th }}, 2013$; revised May 22 ${ }^{\text {nd }}, 2013$; accepted May $29^{\text {th }}, 2013$

Copyright (C) 2013 Anders L. Ekelund, Olle Nilsson. This is an open access article distributed under the Creative Commons Attribution License, which permits unrestricted use, distribution, and reproduction in any medium, provided the original work is properly cited.

\begin{abstract}
Purpose: Drugs that modify the production of cytokines may affect fracture healing. The immunosuppressive drug cyclosporin A is widely used to modify the immune response in transplantations and in treatment of rheumatoid disorders. We wanted to analyze the effect of cyclosporin A on fracture healing and on the development of trauma induced osteopenia. Methods: Experimental tibia fractures were stabilised with intramedullary pins in 26 rabbits. The animals were given $5 \mathrm{mg} / \mathrm{kg} /$ day of cyclosporin A or placebo for 5 weeks. Bone mineral content, callus volume and biomechanical testing were performed on both tibias and femurs. Results: At 5 weeks cyclosporin A treatment resulted in increased bone mineral content and increased callus volume of the fractured bone. The femora on the operated side had significantly lower bone mineral content compared to the non-operated side. This trauma induced osteopenia was unaffected by cyclosporin A treatment. Failure torque and stiffness of the tibia and femora were similar in both groups. Interpretation: Cyclosporin A stimulates bone formation in fracture repair. The mechanism is unclear, but a direct or cytokine mediated effect on bone forming cells, or enhanced bone induction resulting in increased bone formation, is possible.
\end{abstract}

Keywords: Callus; Cyclosporin A; Osteopenia; Tibia Fractures

\section{Introduction}

The immunosuppressant drug cyclosporin A (CsA) has dramatically improved graft survival after transplantation. However, a frequent complication to this treatment is the development of osteopenia as well as fractures [15]. Little is known about the mechanisms behind these effects. Fracture healing is a complex process of tissue regeneration that may lead to the restoration of skeletal integrity [4]. Remodeling then results in adaptation of the bone to functional requirements. A great number of substances with the ability to modify bone cell proliferation and activity, such as bone morphogenetic proteins and different cytokines, have been identified at the site of fractures [6-8]. These substances are involved in the regulation of fracture repair. In addition, cytokines are

\footnotetext{
*Funding sources: The study was supported by grants from the Swedish Medical Research Council. Grant number B9517X-06577-12A. There were no conflicts of interest.

\#Authorship: Both authors jointly designed the study, performed the study, collected and analyzed data, and wrote the paper.

${ }^{\dagger}$ Corresponding author.
}

involved in the pathophysiological changes that occur in different tissues, including bone, in response to trauma $[6,9,10]$. Consequently, drugs that modulate the production of cytokines may affect fracture healing. CsA has gained rapid and widespread use in transplantation surgery and in the treatment of rheumatoid disorders due to its immunosuppressive activity involving inhibition of the production of cytokines, particularly interleukin 2 , involved in the activation and proliferation of T-cells [11]. Earlier studies on bone induction have shown that CsA enhances bone induction in xenogeneic demineralized bone matrix (rabbit) implanted heterotopically in rats $[9,10]$. Furthermore, it was noted that CsA increased bone turnover in the orthotopic bone [10]. The purpose of the present study was to analyze the effect of cyclosporin A on fracture healing in vivo, and on the development of trauma induced osteopenia in the fractured limb.

\section{Materials and Methods}

Twenty-six adult male NZW/NZB rabbits (weight 3 - 4 
$\mathrm{kg}$ ) were used. The animals were housed in individual cages and allowed free access to water and standard laboratory diet. The study was approved by the local Animal Research Ethics Committee at Uppsala University (C14292). "Principles of laboratory animal care" (NIH publication No. 85-23, revised 1985) were followed, as well as the current version of the Swedish Law on the Protection of Animals.

Treatment with CsA: CsA was dissolved in $1 \mathrm{ml}$ of $95 \%$ ethanol, and diluted in castor oil to a concentration of $20 \mathrm{mg} / \mathrm{mL}$. The animals were randomized into two groups (15 in the treatment group, 11 in the control group). The rabbits in the treatment group were given daily subcutaneous injections of the solution, $5 \mathrm{mg} / \mathrm{kg}$ bodyweight, starting two days prior to surgery. The rabbits in the control group were treated with the same solution without CsA. The levels of CsA were determined weekly using a RIA-test (CYCLO-trac SP ${ }^{\circledR}$-Whole Blood RIA kit, Incstar Corp, Stillwater, MN, USA).

Surgery: The surgical procedures were performed under neurolept analgesia $(1 \mathrm{ml} / \mathrm{kg}$ bodyweight, Hypnorm, Leo, Helsingborg, Sweden). The left tibia was approached through an anterolateral incision. At the middle of the tibia a small cut was made through the anterior cortex with a small rongeur. A three point bending force was applied by hand until the tibia fractured. In most instances an oblique, slightly comminuted fracture occurred. A small incision was made lateral to the patella tendon, and 2 - 3 intramedullary pins ( 1 to $3 \mathrm{~mm}$ in diameter) were percutaneously introduced into the medullary cavity until the fracture was stable. The wounds were closed and a cast applied for ten days with dorsiflexion of the foot and 90 degrees of flexion of the knee to improve rotational stability. The animals were randomly taken from the two groups to surgery, and the surgeon was unaware of the treatment given to the rabbits.

The animals were given a saline solution (Rehydrex, Pharmacia-Upjohn, Stockholm, Sweden) subcutaneously (100 ml/kg bodyweight/day) for 2 - 4 days until they had recovered from surgery. Temgesic (Meda, Göteborg, Sweden) was used for pain relief $(0.02-0.05 \mathrm{mg} / \mathrm{kg}$ bodyweight subcutaneously every 8 to 12 hours). Five weeks after surgery the rabbits were sacrificed by a lethal intravenous injection of ethanol/phenobarbital. All tibias and femora were collected and dissected free of soft tissues. The intramedullary pins were removed before the bones were radiographed and frozen at $-80^{\circ} \mathrm{C}$.

Bone mineral content: All measurements were performed on intact bones. The femora and tibias of all animals were scanned transversely in $2 \mathrm{~mm}$ increments with an equal number of scans for all bones. The starting points were $15 \mathrm{~mm}$ above the ankle on the tibias and 20 $\mathrm{mm}$ above the knee joint on the femora. A single photon bone mineral scanner was used (Nuclear Data, Uppsala, Sweden) with $\mathrm{I}^{251}$ as the radiation source. The bone mineral content of the tibias and femora from the operated side and from the non-operated side was calculated for the scanned area, and the ratio between the operated and non-operated side was used for statistical comparison between sides and between the treatment group and the control group. The Mann-Whitney non-parametric test and the one-sample t-test were used for the statistical analyses.

Callus: The amount of callus in the fractured tibias was estimated by calculating a callus area using the following technique: The fractured tibias were radiographed in two perpendicular projections. Using these radiographs, the external callus was manually traced, resulting in two callus figures from each film. These four "callus areas" from each tibia were scanned into a computer and digitised. Each area was then calculated by a computerised mapping system (software AutoKa-Pc, developed by National Landsurvey, Gävle, Sweden) and expressed in square millimeters. The total external callus area from each film was calculated, and the mean value of the callus area from the two different projections from each tibia was used. The Mann-Whitney non-parametric test was used for statistical analyses.

Torsional tests: The bones were fastened to fixation devices with the aid of an alloy (Alloy 136, WilliamRowland Ltd., Sheffield, England) with a melting point of $58^{\circ} \mathrm{C}$ for torsional testing. The bones were submerged $1.2-1.5 \mathrm{~cm}$ into the alloy to a level between the metaphyses and diaphyses. The torsional strength was measured at an inward twist of 6 degrees/second. From the load-deformation curve the maximum torque capacity $(\mathrm{Nm})$, and the stiffness $(\mathrm{Nm} /$ degree) were calculated. The fracture pattern at failure was classified as failure through the fracture site or through intact bone. These results were then used to compare the operated and non-operated sides and to compare the treatment group with the control group. Normalised failure torque and stiffness were analysed by calculating the ratio between operated bones and non-operated bones in all animals in which a complete pair of bones was available. The Mann-Whitney non-parametric test, the one-sample Ttest and linear regression analyses were used for statistical analyses.

\section{Results}

Two rabbits died within two weeks of surgery (one from the control group and one from the CsA group). Three more rabbits died between 2 - 5 weeks, leaving eleven rabbits in the treatment group and ten in the control group. Two femora and one tibia broke at removal of the bones and were therefore excluded from torsional testing. 
Radiographic analyses revealed one possible delayed union in the treatment-group. The rest of the fractures were radiographically healed (Figure 1).

The mean CsA level in venous blood samples at the time of surgery was $62 \pm 19 \mathrm{ng} / \mathrm{mL}$ and at five weeks it was $160 \pm 39 \mathrm{ng} / \mathrm{mL}$.

Bone mineral content: Bone mineral content analysis revealed that the cyclosporin A treated group had significantly higher BMC values in the scanned fracture area than the control group (Table 1). The ratio between operated and non-operated tibias was $1.82 \pm 0.36$ in the CsA treated group compared to $1.41 \pm 0.15$ in controls, $p$ $<0.01$. Furthermore, the femora on the operated side had significantly lower BMC values than the femora on the non-operated side, with a ratio $0.88 \pm 0.05(\mathrm{p}<0.001)$. This difference was unaffected by cyclosporin A treatment $(0.88 \pm 0.05$ in the control group, $0.89 \pm 0.06$ in the CsA group).

Callus area: The mean external callus area was $77 \pm$ $36 \mathrm{~mm}^{2}$ in the control group and $177 \pm 56 \mathrm{~mm}^{2}$ in the treatment group. This difference was statistically significant $(\mathrm{p}<0.001)$. The difference in bone mineral content between operated and non-operated tibia correlated to

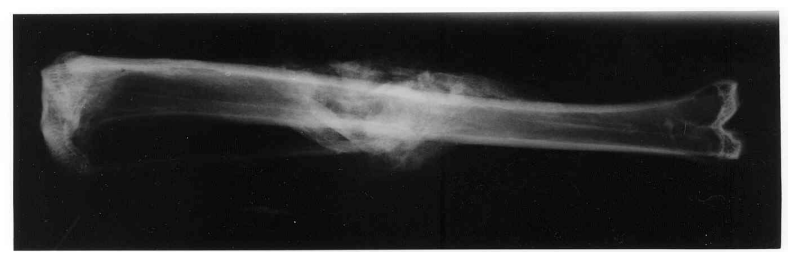

(a)

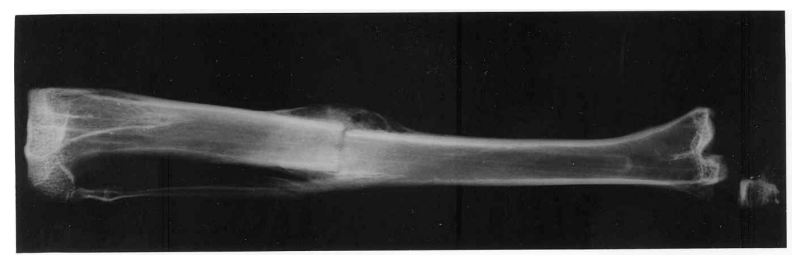

(b)

Figure 1. Radiographs five weeks after a tibia fracture from (a) the control group and (b) the cyclosporin A treated group.

Table 1. Bone mineral content (BMC) of tibias and femora expressed as the mean ratio between BMC values for the operated side and the non-operated side five weeks after an unilateral tibia fracture.

\begin{tabular}{cccc}
\hline Treatment & BMC ratio tibia & BMC ratio femur & N \\
\hline Control & $1.41 \pm 0.15$ & $0.88 \pm 0.05$ & 10 \\
Cyclosporin & $1.82 \pm 0.36$ & $0.89 \pm 0.06$ & 11 \\
$5 \mathrm{mg} / \mathrm{kg} /$ day & $\mathrm{p}<0.01$ & $\mathrm{NS}$ & \\
\hline
\end{tabular}

Values are the mean ratio between operated side/non-operated side \pm SD. NS denotes not significant $(\mathrm{p}>0.05)$. the mean callus area (all tibias $\mathrm{r}^{2}=0.76, \mathrm{p}<0.001, \mathrm{CsA}$ $\mathrm{r}^{2}=0.64, \mathrm{p}<0.05$, control $\mathrm{r}^{2}=0.53, \mathrm{p}<0.01$ ) (Figure 2).

Torsional tests: Twelve bones, 6 femora and 6 tibia, had to be excluded from the biomechanical testing (three due to fracture at removal, one due to delayed union, and eight due unsatisfactory fixation at the time of testing). Furthermore, one of the femora from the non-operated side had a very low value for failure torque due to a technical problem during data collection, and this value was therefore excluded. Three tibias from the CsA group and one from the control group failed through the original fracture. Mean failure torque and stiffness of the tibias and the femora were unaffected by CsA treatment (Table 2).

Mean normalised failure torque for all tibia and femur bone-pairs (operated vs nonoperated) was significantly decreased in both controls and the cyclosporin treated group (Table 3). Normalised stiffness was increased in tibias and decreased in femora on the operated side in controls. A similar trend was seen in the CsA treated group, but it was not statistically significant.

\section{Discussion}

In the present study CsA treatment was found to increase bone mineral content and callus volume of tibia fractures in the rabbit. The fractures and the fracture treatment induced a decrease in bone mineral content of the femurs, as well as in the strength of both the femora and tibias, on the fractured side-but this trauma induced osteopenia was not affected by CsA treatment.

Earlier studies on the effect of cyclosporin on bone have given conflicting results. Increased bone turnover of orthotopic bone with increased bone resorption, balanced

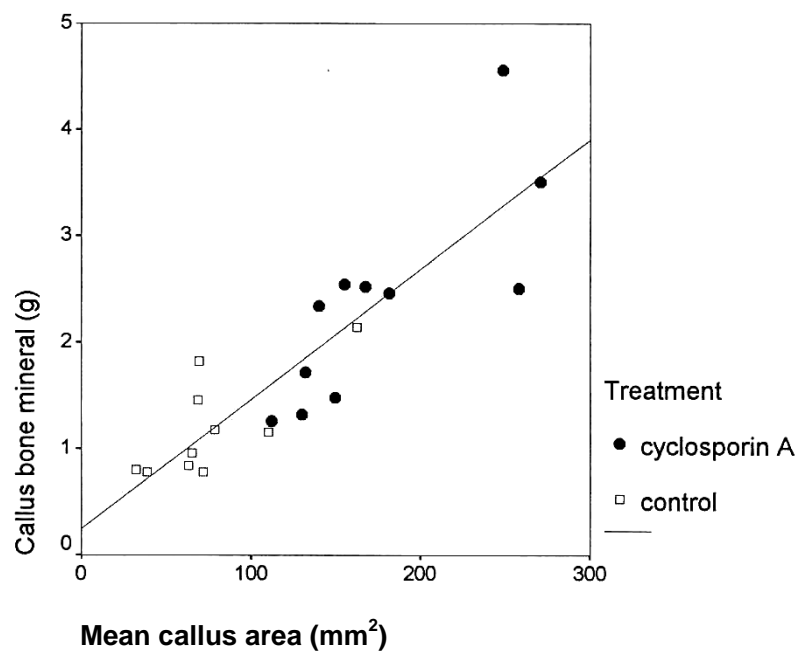

Figure 2. Correlation between the difference in bone mineral content between operated and non-operated tibia and mean callus area. 
Table 2. Failure torque ( $\mathrm{Nm})$ and stiffness ( $\mathrm{Nm}$ /degrees) of tibia and femur five weeks after a unilateral tibia fracture.

\begin{tabular}{|c|c|c|c|c|c|c|}
\hline \multirow[t]{2}{*}{ Side/Treatment } & \multicolumn{3}{|c|}{ Tibia } & \multicolumn{3}{|c|}{ Femur } \\
\hline & Torque & Stiffness & $\mathrm{N}$ & Torque & Stiffness & $\mathrm{N}$ \\
\hline \multicolumn{7}{|l|}{ Operated } \\
\hline Control & $2.93 \pm 0.78$ & $0.24 \pm 0.05$ & 9 & $5.51 \pm 0.69$ & $0.42 \pm 0.1$ & 10 \\
\hline \multirow[t]{2}{*}{ Cyclosporin } & $2.95 \pm 0.54$ & $0.21 \pm 0.04$ & 7 & $5.09 \pm 1.13$ & $0.39 \pm 0.04$ & 7 \\
\hline & NS & NS & & NS & NS & \\
\hline \multicolumn{7}{|l|}{ Non-operated } \\
\hline Control & $3.79 \pm 0.5$ & $0.21 \pm 0.05$ & 10 & $6.54 \pm 0.62$ & $0.51 \pm 0.07$ & 10 \\
\hline \multirow[t]{2}{*}{ Cyclosporin } & $3.6 \pm 0.52$ & $0.2 \pm 0.05$ & 10 & $6.39 \pm 0.89$ & $0.44 \pm 0.08$ & 8 \\
\hline & NS & NS & & NS & NS & \\
\hline
\end{tabular}

The Mann-Whitney test used for statistical analyses. $\mathrm{SD}=$ standard deviation. NS denotes not significant $(\mathrm{p}>0.05)$.

Table 3. Ratio of failure torque $(\mathrm{Nm})$ and stiffness $(\mathrm{Nm} /$ degrees) between operated and non-operated side five weeks after a unilateral tibia fracture.

\begin{tabular}{|c|c|c|c|c|c|c|}
\hline \multirow[t]{2}{*}{ Treatment } & \multicolumn{2}{|c|}{ Tibia } & \multicolumn{4}{|c|}{ Femur } \\
\hline & Torque & Stiffness & $\mathrm{N}$ & Torque & Stiffness & $\mathrm{N}$ \\
\hline \multirow[t]{2}{*}{ Control } & $0.79 \pm 0.21$ & $1.19 \pm 0.18$ & 9 & $0.85 \pm 0.14$ & $0.83 \pm 0.17$ & 10 \\
\hline & $\mathrm{p}<0.05$ & $\mathrm{p}<0.05$ & & $\mathrm{p}<0.01$ & $\mathrm{p}<0.01$ & \\
\hline \multirow[t]{2}{*}{ CsA } & $0.82 \pm 0.17$ & $1.08 \pm 0.31$ & 6 & $0.82 \pm 0.16$ & $0.92 \pm 0.23$ & 6 \\
\hline & $\mathrm{p}<0.05$ & NS & & $\mathrm{p}<0.05$ & NS & \\
\hline \multirow{2}{*}{ All pairs } & $0.80 \pm 0.19$ & $1.15 \pm 0.24$ & 15 & $0.84 \pm 0.15$ & $0.86 \pm 0.19$ & 16 \\
\hline & $\mathrm{p}<0.01$ & $\mathrm{p}<0.05$ & & $\mathrm{p}<0.001$ & $\mathrm{p}<0.01$ & \\
\hline
\end{tabular}

Values are presented as the mean ratio between operated and non-operated side. $\mathrm{SD}=$ standard deviation. NS denotes not significant $(\mathrm{p}>0.05)$.

by an increased bone formation, have been reported $[9,10]$. In addition, Orcel et al. found that CsA stimulated bone formation in rat bone and inhibited bone resorption without affecting PTH or vitamin D [12]. In contrast, others have reported that CsA treatment in rats causes a high turnover osteoporosis due to increased bone resorption [3,12-14] This is in agreement with the finding of early bone loss in patients receiving CsA and glucocorticoids after heart transplantation [15]. However, the combination therapy used in transplantation patients makes it difficult to detect specific effects of the different drugs [3,5]. CsA treatment has been found to correlate to a slight osteoclast stimulation, osteblast suppression and decreased bone mineral density in renal transplant patients [1]. Under experimental conditions high-dose CsA treatment has been shown to induce osteopenia in both trabecular and cortical bone in the rat [16]. Interestingly, in a large series of patients treated with immunomodulating drugs no association to increased fracture risk was noted in patients treated with cyclosporin [2]. Most studies on the effects of cyclosporin A on bone have been performed on intact bone, while the fracture causes a complex reparative response that may be modulated by CsA in a different manner compared to steady state conditions. Thus, it is difficult to compare the present results with earlier reports. In one study of the effects of CsA on fracture healing in rats, no effects of CsA on the strength of the fractures were found [17]. However, callus formation, or morphology of the healing, was not studied. Also, short term CsA treatment induced hypertrophic changes with high-turnover bone loss in vascularized bone grafts in the rat [13].

The effects of cyclosporin are dependent on the concentration of the drug, and this may partly explain the conflicting results reported in the literature $[11,18]$. In the present study the serum levels of cyclosporin were found to be in the therapeutic interval, $100-800 \mathrm{ng} / \mathrm{mL}$. In vitro, interleukin production and release are almost totally blocked at a cyclosporin serum level of $100 \mathrm{ng} / \mathrm{mL}$, and toxic side effects are commonly reported when the concentration reaches $800 \mathrm{ng} / \mathrm{mL}$ [19].

The mechanism for the enhanced callus formation 
found in the present study is unclear, but may be due to enhanced osteoinduction or due to stimulation, direct or cytokine mediated, on bone forming cells. Earlier studies on bone induction have showed that cyclosporin A treatment enhances bone formation in heterotopically placed allogeneic and xenogeneic demineralized bone matrix [9], and enhances the incorporation of vascular free grafts in rats [20]. The relative importance of bone induction in fracture repair is unknown. However, bone morphogenetic proteins have been identified in fracture repair and may be important regulators of cell differentiation during fracture healing [6-8]. Thus, enhanced osteoinduction by cyclosporin A may contribute to the increased callus formation.

The enhanced turnover of traumatized bone- the regionally acceleratory phenomenon (RAP), is necessary for normal fracture healing and is regulated, at least in part, by prostaglandins - especially $\mathrm{PGE}_{2}[4,8]$. Interestingly, $\mathrm{PGE}_{2}$ has been shown to counteract high turnover osteopenia of in part bone caused by CsA treatment in rats [21]. Thus, CsA may potentiate the RAP at the fracture site and enhance the repair process. In addition, fracture healing in thymectomized mice is impaired healing compared to controls, and participation of T-cells in bone regeneration has been suggested. Thus, direct effects on T-cells activity by CsA may be involved in the enhanced callus formation. In agreement, splenectomy has been found to result in delayed fracture healing. Furthermore, transforming growth factor $\beta$ (TGF $\beta$ ) has been identified at the site of fracture repair and a regulatory role for $\operatorname{TGF} \beta$ in bone remodeling and fracture repair has been suggested $[6,8,22]$. Recently it was shown that CsA stimulated the expression of $\operatorname{TGF} \beta$ in human blood cells [22].

CsA treatment caused an enhanced callus formation resulting in larger callus. Furthermore, the strong correlation between callus area and bone mineral content of the external callus shows that the concentration of bone mineral in the calluses, e.g. the quality of the newly formed bone, was similar in both groups and largely independent of callus volume [23]. Thus, CsA has a stimulating effect on bone formation in fracture healing. However, the increased callus was not reflected in increased strength, but since the mineral content correlates strongly to the strength of bone, it might be assumed that the fracture healing can proceed and result in stronger calluses in the cyclosporin treated rabbits than in the controls due to the increased amount of callus and bone mineral content. Similar findings have been noted in rats following skeletal reconstruction with vascularized allogeneic bone [17], but in such a model the immunosupressing effect by CsA cannot be differentiated from enhancing effects on bone healing.

The bone mineral content and strength were reduced in the femora on the operated side in both groups. This is in agreement with clinical studies on the effects of immobilization after fractures and surgery of the hip [24,25]. This trauma induced osteopenia was not affected by CsA treatment. Thus, it seems that CsA has specific effects on callus formation that are different from the effects on intact bone.

In summary, CsA was found to significantly enhance callus formation of fractured rabbit tibia. CsA did not induce changes in bone mineral content or biomechanical properties of intact bone. These results suggest that CsA stimulates bone formation in fracture repair. The mechanism is unclear, but a direct or cytokine mediated effect on bone forming cells, or enhanced bone induction resulting in increased bone formation, is possible.

\section{REFERENCES}

[1] A. M. Cueto-Manzabo, S. Konel, V. Crowley, et al., "Bone Hisptopathology and Densitrometry Comparison between Cyclosporine a Monotherapy and Prednisolone Plus Azathioprine Dual Immunosuppression in Renal Transplant Patients," Transplantation, Vol. 75, No. 12, 2003, pp. 2053-2058. doi:10.1097/01.TP.0000068869.21770.F6

[2] M. Mazzantini, O. Di Munno, L. Sinigaglia, et al., "Effects of Cyclosporine A on Bone Density in Female Rheumatoid Arthritis Patients: Results from a Multicenter Cross-Sectional Study," Clinical and Experimental Rheumatology, Vol. 25, No. 5, 2007, pp. 700-715.

[3] P. Tannirandorn and S. Epstein, "Drug-Induced Bone Loss," Osteoporosis International, Vol. 11, No. 8, 2000, pp. 637-659. doi:10.1007/s001980070062

[4] H. M. Frost, "The Biology of Fracture Repair," Clinical Orthopaedics and Related Research, Vol. 248, 2000, pp. 283-293.

[5] P. Vestergaard, L. Rejnmark and L. Mosekilde, "Methotrexate, Azatioprine, Cyclosporine and Risk of Fracture," Calcified Tissue International, Vol. 79, No. 2, 2006, pp. 69-75. doi:10.1007/s00223-006-0060-0

[6] M. E. Bolander, "Regulation of Fracture Repair by Growth Factors," Proceedings of the Society for Experimental Biology and Medicine, Vol. 200, No. 2, 1992, pp. 165170. doi:10.3181/00379727-200-43410A

[7] M. P. G. Boström, J. M. Lane, W. S. Berberian, et al., "Immunolocalization and Expression of Bone Morphogenetic Proteins 2 and 4 in Fracture Healing," Journal of Orthopaedic Research, Vol. 13, No. 3, 1995, pp. 357367. doi:10.1002/jor.1100130309

[8] T. A. Einhorn, "Enhancement of Fracture Healing," The Journal of Bone \& Joint Surgery, Vol. 77, No. 6, 1995, pp. 940-956.

[9] A. Ekelund and O. Nilsson, "Effects of Cyclosporin A on Experimental New Bone Formation in Rats," Clinical Orthopaedics and Related Research, No. 284, 1992, pp. 288-298.

[10] A. Ekelund and O. Nilsson, "Effects of Cyclosporin A on 
Bone Turnover and on Resorption of Demineralized Bone Matrix," Clinical Orthopaedics and Related Research, No. 326, 1996, pp. 127-134. doi:10.1097/00003086-199605000-00015

[11] D. Bunjes, G. Hardt, M. Röllinghoff and H. Wagner, "Cyclosporin A Mediates Immunosuppression of Primary Cytotoxic T Cell Responses by Impairing the Release of Interleukin 1 and Interleukin 2," European Journal of Immunology, Vol. 11, No. 8, 1981, pp. 657-661. doi:10.1002/eji.1830110812

[12] P. Orcel, J. Bielakoff, D. Modrowski, L. Miravet and M. C. De Vernejoul, "Cyclosporin A Induces in Vivo Inhibition of Resorption and Stimulation of Formation in Rat Bone," Journal of Bone and Mineral Research, Vol. 4, No. 3, 1989, pp. 387-391. doi:10.1002/eji.1830110812

[13] C. Wada, M. Karaoka, H. Seto, et al., "High-Turnover Osteoporosis Is Induced by Cyclosporin A in Rats," Journal of Bone and Mineral Metabolism, Vol. 24, No. 3, 2006, pp. 199-205. doi:10.1007/s00774-005-0672-x

[14] G. Movsowitz, S. Epstein, M. Fallon, et al., "Cyclosporin-A in Vivo Produces Severe Osteopenia in the Rat: Effect of Dose and Duration of Administration," Endocrinology, Vol. 123, No. 5, 1988, pp. 2571-2577. doi:10.1210/endo-123-5-2571

[15] D. Thiebaud, M. A. Krieg, D. Gillard-Berguer, et al., "Cyclosporin Induces High Bone Turnover and May Contribute to Bone Loss after Heart Transplantation," European Journal of Clinical Investigation, Vol. 26, No. 7, 1996, pp. 549-555. doi:10.1210/endo-123-5-2571

[16] M. Abdelhadi, B. G. Ericzon, K. Hultenby, G. Sjöden, F. P. Reinholt and J. Nordenström, "Structural Skeletal Impairment Induced by Immunosupressive Therapy in Rats: Cyclosporine A vs Tacrolimus," Transplant International, Vol. 15, No. 4, 2002, pp. 180-187. doi:10.1111/j.1432-2277.2002.tb00149.x

[17] T. Ohno, M. Shigetomi, K. Ihara, T. Matsunaga, T. Hashimoto, H. Kawanano, T. Sugiyama and S. Kawai, "Skeletal Reconstruction by Vacularized Allogenic Bone Transplantation: Effects of Statins in Rats," Transplantation, Vol. 76, No. 5, 2003, pp. 869-871. doi:10.1111/j.1432-2277.2002.tb00149.x
[18] E. Del Pozo and J. Zaff, "Skeletal Growth and Bone Density as Sensitive Parameters in Experimental Arthritis: Effects of Cyclosporin A," Bone, Vol. 15, No. 6, 1994, pp. 625-628. doi:10.1111/j.1432-2277.2002.tb00149.x

[19] E. Irschik, H. Tilg, D. Niederwieser, G. A. Gastl, et al., "Cyclosporin Blood Levels Do Correlate with Clinical Complications," Lancet, Vol. 324, No. 8404, 1984, pp. 692-693. doi:10.1111/j.1432-2277.2002.tb00149.x

[20] T. Tsubone, M. Shigetomi, K. Ihara, et al., "Hypertrophy of Vascularized Bone Isografts in Rats Treated with Cyclosporine A," Calcified Tissue International, Vol. 73, No. 4, 2003, pp. 393-399. doi:10.1111/j.1432-2277.2002.tb00149.x

[21] I. A. Katz, W. S. S. Jee, I. I. Joffe, et al., "Prostaglandin E2 Alleviates Cyclosporin A-Induced Bone Loss in the Rat," Journal of Bone and Mineral Research, Vol. 7, No. 10, 1992, pp. 1191-1200. doi:10.1111/j.1432-2277.2002.tb00149.x

[22] G. T. Shin, A. Khanna, R. Ding, et al., "In Vivo Expression of Transforming Growth Facto R-Beta 1 in Humans: Stimulation by Cyclosporine," Transplantation, Vol. 65, No. 3, 1998, pp. 313-318. doi:10.1111/j.1432-2277.2002.tb00149.x

[23] L. Nordsletten, T S. Kaastad, S. Skjeldal, et al., "Fracture Strength Prediction in Rat Femoral Shaft and Neck by Single Photon Absorptiometry of the Femoral Shaft," Journal of Bone and Mineral Research, Vol. 25, No. 1, 1994, pp. 39-46. doi:10.1111/j.1432-2277.2002.tb00149.x

[24] M. M. Petersen, P. M. Gehrchen, P. K. Nielsen and B. Lund, "Loss of Bone Mineral of the Hip Assessed by DEXA Following Tibial Shaft Fractures," Bone, Vol. 20, No. 5, 1997, pp. 491-495. doi:10.1111/j.1432-2277.2002.tb00149.x

[25] K. Kawana, M. Takahashi, K. Kushida, et al., "The Effect of Cyclosporin a Administration on Bone Metabolism in the Rat Evaluated by Biomechanical Markers," Journal of Endocrinological Investigation, Vol. 19, 1996, pp. 499504. 